\section{Cardio-respiratory effects of change of body position}

Thomas J. Coonan BA MDCM DA(Tor) FRCP(c), Charles E. Hope MBCH B FFARCS FRCP(C)

\section{CONTENTS}

Introduction

Anaesthesia and posture

The circulatory system

The erect position

The sitting position in anaesthesia

Chronic circulatory overload

Paradoxical air embolism

The head-down position

The lateral and prone positions

The respiratory system

Functional residual capacity

Vital capacity

The distribution of inspired gases

Pulmonary blood flow

Conclusion

\section{Introduction}

"The immunity against circulatory failure in the upright posture is maintained by daily training, and is so deeply ingrained in the texture of human nature that we become aware of its existence only when it fails ..."

Healthy active man spends the greater part of his life in the erect position - walking, running, standing or sitting. Unlike some other animal species, man assumes a recumbent posture only to rest or to sleep, even then never entirely immobile. The erect "active" position then may be considered as man's normal or "physiological" state. In this condition he remains in equilibrium with his environment. This equilibrium, the result of active and coordinated physiological processes, was termed "homeostasis" by Cannon in 1939.2 Its stability can be threatened by prolonged bed rest, disease and drugs, including anaesthetic drugs, all of which may interfere with normal homeostatic mechanisms.

Anaesthesia and posture

Anaesthetised patients can be placed in a variety of surgical positions which may adversely affect both circulation and ventilation. Changes in body position lead to changes in hydrostatic pressure which affect both systemic and pulmonary circulations. Fortunately, general principles applicable to most positions can be developed. These have been summarised in an authoritative review of the physiology of postural change. ' Gravitational forces act on the lungs and the adjacent tissues and organs and, together with the effect on the pulmonary circulation, are responsible for significant respiratory physiological effects. In this review, the circulatory and respiratory systems will be considered separately, but it should not be forgotten that it is not possible to interpret a physiological response to change in body position without considering the interaction between these two system.

\section{The circulatory system}

In normal active and conscious man, fluctuations in tissue blood flow occur, naturally and spontaneously. These were first described in early plethysmographic studies, ${ }^{3,4}$ and were considered by Burch" to be evidence of some "homeostatic" mechanism by which peripheral tissucs were guaranteed a blood supply appropriate to their need. When man assumes the supine position and lies completely immobile, these spontancous volume fluctuations progressively diminish until, after approximately one hour, they disappear ${ }^{5}$ At this stage it requires a great effort for the human subject to remain motionless. With time, discomfort sets in and increases progressively. Eventually, even the peripheral blood flow diminishes.

On induction of anaesthesia, an initial peripheral vasodilatation results in an augmentation of the peripheral blood flow unless hypocarbia, hypother-

From the Dalhousie University Department of Anaesthesia, Sir Charles Tupper Medical Building, Halifax, Nova Scotia B3H $4 \mathrm{H} 7$. 
mia or hypovolaemia is present. Then, in time, as in conscious subjects, the spontaneous volume fluctuations disappear. It is not until anaesthesia is terminated and the subject begins to react and move that the spontaneous volume fluctuations in the peripheral vascular system reappear.

Ideally, the heart provides an adequate circulation to all tissues at minimal energy cost. It should not have to work against gravity or a raised peripheral vascular resistance. The supine position should best satisfy this criterion in that gravity will have little effect on arterial distribution or venous return.

The pressure at any point in the vascular system, whether arterial or venous, is effected by the position of the body and the gravitational forces acting on it. In standing subjects, since the long axis of the body is parallel to the direction of gravitational pull, the pressures in the upper part of the body fall while the pressures in the dependent part rise. The hydrostatic pressure differential is dependent on the vertical height difference between one part of the body and another. This translates into $2 \mathrm{mmHg}$ for each $2.5 \mathrm{~cm}$ vertical height, which, in the normal male represents about $140 \mathrm{mmHg}$ from head to toe. Thus, with a mean arterial pressure of $90 \mathrm{mmHg}$ at heart level, the pressure in the cerebral arteries will be approximately $25 \mathrm{mmHg}$ lower $(90-25=65 \mathrm{mmHg})$ while that in the foot will be approximately $115 \mathrm{mmHg}$ higher $(90+115=$ $205 \mathrm{mmHg}$ ). A similar effect is seen in the low pressure (venous) side of the circulation.

Hydrostatic forces act regardless of the position of the body, but always parallel to the direction of gravitational pull. Thus in the supine position, while a pressure differential is still seen with vertical height differences, the pressure along the long axis of the body will be virtually the same, whether at the heart, the head or the foot.

The concept of the Hydrostatic Indifferent Point (HIP) is useful. This represents the transition zone in which intravascular pressures stay relatively constant, and represents a narural reference point for hydrostatic shifts in the circulation. ${ }^{6}$ At this point, the intravascular pressures and the vessel sizes are not affected by the hydrostatic forces in the circulation. The HIP is specific for any given posture. Below the HIP the vascular bed will be engorged by blood draining from regions above. The effect of change of posture on venous return to
TABLE I Cardiovascular sysiem. Effect of change in body position of conscious and anaesthetised man from the supine to the seated position

\begin{tabular}{|c|c|c|}
\hline & $\begin{array}{l}\text { Change from } \\
\text { conscious } \\
\text { supine to seased }\end{array}$ & $\begin{array}{l}\text { Change from } \\
\text { anaesthetised } \\
\text { supine to seated }\end{array}$ \\
\hline Blood pressure & $\uparrow 0-20 \%$ & $\uparrow 0-40 \%$ \\
\hline A. $\mathrm{VO}_{2}$ difference & $\uparrow 50-60 \%$ & \\
\hline Cardiac output & $\downarrow 20-40 \%$ & $\downarrow 12-20 \%$ \\
\hline $\begin{array}{l}\text { Heart rate } \\
\text { Systemic vascular }\end{array}$ & $\uparrow 15-30 \%$ & $\leftrightarrow \uparrow$ \\
\hline resistance & $\uparrow 30-60 \%$ & $\uparrow 50-80 \%$ \\
\hline $\begin{array}{l}\text { Pulmonary vascular } \\
\text { resistance }\end{array}$ & $\uparrow$ & \\
\hline Stroke volume & $\downarrow 40-50 \%$ & \\
\hline Central blood volume & $\downarrow 400 \mathrm{ml}$ & \\
\hline $\begin{array}{l}\text { Left and right atrial } \\
\text { pressures }\end{array}$ & $\downarrow$ & $\downarrow(\mathrm{R}<\mathrm{L})$ \\
\hline Cerebral blood flow & $\downarrow 20 \%$ & $\downarrow 15 \%$ \\
\hline Renal blood fow & $\downarrow 30 \%$ & \\
\hline Hepatic blood flow & $\downarrow$ (slight) & \\
\hline
\end{tabular}

NOTE: Conscious supine and anaesthetised supine are separate control baselines and are not compared with each other.

Changes indicated as: $\uparrow$ increase, $\downarrow$ decrease, $\leftrightarrow$ unchanged.

the heart, and thus the cardiac filling pressures and cardiac output, depends on the position of the HIP relative to the heart.

In the arterial system, active changes in cardiac output and peripheral resistance usually obscure passive hydrostatic pressure effects. However, in the venous system, pressure is minimally affected by physiologic changes in either cardiac output or peripheral resistance. Accordingly, venous pressure changes resulting from alterations in position are due predominantly to changes in hydrostatic pressure.

\section{The erect position}

Cardiovascular changes associated with the change from the supine to the seated position are summarized in Table $\mathrm{I}$.

When supine man assumes the erect position, blood is transferred from the upper body, to the lower body. The HIP shifts from heart level to a position just below the diaphragm, cardiac venous filling pressures are reduced, and the normal response is an increase in sympathetic tone, a decrease in parasympathetic tone, activation of the renin-angiotensin-aldosterone system and the retention of fluid and electrolyte by the kidney. ${ }^{7,8}$ The 
pulse rate increases (up to 30 per cent), and systemic vascular resistance increases (30-60 per cent) due, primarily, to constriction of the arterial and arteriolar circulation. 1,9 Surprisingly, the tone in the capacitance part of the circulation does not change significantly. ${ }^{1}$ Intra-thoracic blood volume decreases by about $300-500 \mathrm{ml}^{1,10}$ and the left atrial pressure decreases significantly. Right atrial pressure also decrcases but usually less than on the left side of the circulation. This is probably due to the increase in pulmonary vascular resistance, which can double. ${ }^{1,10}$ Cardiac output decreases (20-40 per cent) as does stroke volume ( $40-50$ per cent). Since oxygen consumption does not change significantly, the reduced cardiac output causes the arterio-venous difference in oxygen content to increase in the erect position. ${ }^{1,11}$

The mean arterial pressure remains constant or increases (up to 18 per cent) depending on whether the subject actually stands or undergoes passive tilt. Systolic blood pressure remains relatively constant and changes in mean arterial pressure are largely the result of alterations in diastolic pressure. ${ }^{1,9}$

Renal blood flow decreases significantly in the erect position ( -30 per cent). ${ }^{12}$ Glomerular filtration rate decreases and increases in ADH and aldosterone secretion result in both water and sodium retention. In very obese patients the reduction in renal blood flow is even greater $(-76$ per cent), particularly in the sitting position, probably due to an increase in intra-abdominal pressure. ${ }^{12}$ Hepatic and splanchnic circulatory changes are less than renal and transient. Cerebral blood flow decreases ( -20 per cent) in the erect position. ${ }^{3}$

As might be expected, the responses of the normal subject to positions intermediate between the recumbent and erect positions are in the same direction but of a lesser degree.

These changes are not seen when the position is changed with the subject immersed in water. The presence of an identical external pressure gradient antagonises orthostasis. This is part of the rationale for the bandaging of legs, and the use of anti-gravity suits and anti-shock trousers and similar devices in anaesthesia and acute care medicine. ${ }^{34}$

The sitting position in anaesthesia

It is nowadays rare that the full sitting position, with a vertical spine and dependent legs, is used in anaesthesia. The modified sitting position, with the body elevated towards the vertical, with thighs flexed on the trunk, legs flexed on the thighs and feet close to the level of the heart, is more usually adopted. ${ }^{13}$

The literature suggests that bandaging of the legs, the adoption of the modified sitting position and the careful adjustment of fluid load will go a long way to minimising any extreme response. However, such findings as exist are often specific to a given anaesthetic technique, and extrapolation to other techniques must be done with some reservation.

In fit patients anaesthetised with nitrous oxide, pancuronium and intermittent fentanyl, the change to the sitting position led to a decrease in cardiac output ( -12 per cent), and an increase in systemic vascular resistance $(+50$ per cent), while heart rate and mean arterial pressure did not change significantly. ${ }^{15}$ It must be emphasized, however, that the haemodynamic changes which occurred when the sitting position was assumed from the supine were examined against a baseline of stable anaesthesia and not against pre-induction control values. It is noteworthy that similar changes occur with identical postural changes in conscious healthy man.

Albin et al., in a similar study using nitrous oxide and narcotics (not identified), reported the same haemodynamic alterations but of considerably greater magnitude. Cardiac output fell 20 per cent, systemic vascular resistance increased 80 per cent and mean arterial pressure 38 per cent. ${ }^{16,17}$ These data indicate significantly greater changes than are normally seen in the conscious standing subject and raise serious doubts about the capacity of the compromised patient to compensate for the effects of the sitting position during anaesthesia. It is not clear why the results of these two studies differed, but it is possible that the anaesthetic techniques were significantly different.

Two interesting facts emerge from these studies: ${ }^{15-17}$ first, patients did not demonstrate significant haemodynamic change until a head-up tilt greater than $60 \mathrm{deg}$. was established, and second, the haemodynamic effects of the sitting position progressed for at least one hour after the patient was placed in this position.

It must be emphasized that the sitting position is equivalent to a degree of tilt greater than $60 \mathrm{deg}$. In an oft-quoted study, Stoelting $\mathrm{et}$ al. concluded that the circulatory changes during sodium nitroprusside administration for prolonged controlled hypoten- 
sion in the semi-sitting position were similar to the haemodynamic changes observed during SNP administration in the supine position. ${ }^{18}$ Unfortunately, this study is simply not comparable with those carried out in the sitting position, as the head was elevated only to 30-45 deg. Reports of this study do not always clearly identify that the true modified sitting position was not used. ${ }^{13,19}$

The effects of anaesthesia in the sitting position on organ systems other than the brain have not been documented, and even cerebral blood flow has not received extensive attention. In a study of patients undergoing chemotherapy for cerebral tumours, Tindall showed a decrease of carotid blood flow ( -14 per cent) in the sitting position. ${ }^{20}$ There were many interacting variables: the patients were hyperventilated to a $\mathrm{PaCO}_{2}$ of 22 torr, halothane was used for the anaesthetic and cerebral autoregulation was probably disturbed by the CNS pathology. Nevertheless, the carotid blood flow did decrease to a degree similar to that demonstrated in awake patients. This decrease was also proportional to the decrease in mean arterial pressure at the level of the mid-cerebrum. This must have involved an increase in cerebro-vascular resistance because the hydrostatic effect would have been equally distributed to the intracranial arterial, venous and CSF compartments. The cerebral perfusion pressure should theoretically have remained constant.

It would appear reasonable, on the basis of available evidence, to utilise mean arterial pressure at the level of the Circle of Willis as an index of cerebral blood flow in anaesthetised sitting patients. This logic has been carried further and the arterial pressure at the Circle of Willis has been used to monitor the induction of controlled hypotension for difficult surgery of the posterior fossa in the sitting position. ${ }^{21}$ This may or may not be valid. It has not to our knowledge been studied and, accordingly, cannot be endorsed lightly. Particularly in patients with intracranial space occupying lesions, cerebral blood fow might not passively follow the mean arterial pressure.

In this context, Shenkin et al. ${ }^{22}$ demonstrated that there was no alteration in cerebral blood flow in normal subjects tilted head up to 20 deg. , but that in patients with brain tumours cerebral blood flow decreased ( -20 per cent). There was a concomitant decrease in carotid artery pressure ( -6 per cent). There were only six patients in the tumour group and the results seem to have been skewed by the response of one patient. Nevertheless, the implications of these findings for intensive care and anaesthesia are important.

In summary, while clinical experience indicates that the subject with adequate circulatory reserves can tolerate the sitting position well, care should be taken in utilising this position in patients without circulatory reserve. If the sitting position has to be used in such patients, the fullest possible monitoring, including measurement of pulmonary arterial and pulmonary arterial wedge pressures and cardiac output, should be instituted.

ldeally, cerebral blood flow should be assessed in patients with either marginal cardiovascular reserve or elevated ICP, with the use of cortical evoked potentials or cerebral function monitoring, when the sitting position is being considered.

The response of the normal person to assuming the erect position has been discussed. If this response is inadequate, hypotension can ensue, and may develop rapidly after an initial period of partial compensation. Bradycardia, perhaps due to the activation of Bezold-Jarisch reflexes produced by strong ventricular contraction against an inadequately filled ventricle can be seen. This bradycardia is responsive to atropine; however, cardiac output may not change as a result of this therapy. This type of cardiovascular collapse has been extensively studied and seems to be related to a reduction in arteriolar resistance. ${ }^{23,24}$ Despite profound hypotension, the cardiac output may be maintained. This is a highly dangerous situation as cerebral blood fow decreases despite the maintenance of cardiac output.

Certain patients have difficulty in compensating for the stress of the erect position (see Table II). Predictably, haemornhage and dehydration are poorly tolerated in this position. Chronic orthostatic stress seems necessary for the maintenance of an adequate blood volume; consequently, the chronically bed-ridden patient with reduced blood volume will have difficulty in adjusting to the erect position. ${ }^{25}$ In these patients electrolyte and fluid balance may be deranged. In addition there is a lag in the response of peripheral vascular tone. ${ }^{1}$ Increasing age alone might decrease the ability of man to compensate for orthostatic stress as a result of a decreased sensitivity of the carotid sinus reflex. ${ }^{26}$ Likewise, the chronically hypertensive patient with 
TABLE Il Orthostatic hypotension

Aetiology
Inadequate blood volume
Haemorrhage
Dehydration
Prolonged bed rest
Diuretics
Hypertension
Obstructed venous return
Inadequate baroreceptor mechanisms
Aging
Hypertension
Dependent vascular pooling
Paralysis
Immobility
Varicosities
Idiopathic orthostatic hypotension
Pharmacological
Vasodilalors
Anti-hypertensives
Management
Patient selection and monitoring
Proper positioning
Leg bandaging
G-Suits (anti-shock trousers)
Volume expansion
Optimal ventilatory parameters (I:E ratio; tidal volume;
intrathoracic pressure)

a decreased blood volume 27 and a blunted carotid barorefle $\mathrm{x}^{28}$ has difficulty adjusting to different positions. ${ }^{29}$

Prolonged assumption of the erect position produces progressive pooling of blood into dependent areas through relaxation of the capacitance vessels in the lower part of the body. Effective blood volume decreases further because of the transfer of fluid from the intravascular to extravascular space due to increased intravascular pressures in the lower extremity. ${ }^{1,30}$ Reversal of the position from the erect to the supine will lead to fluid reabsorption from the extravascular space and a reversal of these effects. ${ }^{31}$

If the erect position is maintained, there will be a steady decrease in cardiac filling pressure which may lead to an acute collapse. This is probably the origin of the familiar "Parade Square Collapse." In awake standing man, pooling into dependent areas can be modified by lower extremity muscular contraction. This muscular contraction is absent in the anaesthetised and paralysed subject. These hydrostatic stresses may be modified by firm bandaging of the legs with elastic bandages, adoption of the modified rather than the full sitting position ${ }^{18}$ and expansion of the intravascular volume using CVP monitoring. This may result in a relative fluid overload in the immediate postoperative phase when the patient is lowered to the supine position. In neurosurgical patients this may intensify postoperative oedema and a degree of head elevation should be maintained. In such patients care should be taken that the leg bandages are removed only after the patient has recovered sufficiently to be able to respond to circulatory adaptive demands and careful observation must be continued to detect any syncopal events.

Despite an adequate blood volume, some patients are unable to marshal an adequate increase in vascular tone on assuming the erect position. This may be due to an innate autonomic imbalance as in idiopathic orthostatic hypotension, ${ }^{32}$ or may result from diuretic, sympatholytic or direct vasodilator therapy. There is evidence that patients who are beta-blocked can tolerate assumption of the erect position reasonably well. ${ }^{7,33}$

\section{Chronic circulatory averload}

Patients with chronic circulatory overload react quite differently. Their blood volume is already expanded, there is already an increase in peripheral arterial and venous tone, and the transfer of blood out of the thorax in effect shifts the left ventricle to a more favourable position on the Frank-Starling curve. ${ }^{34.35}$ Cardiac output is maintained and there is no significant increase in systemic vascular resistance. Similar effects may be seen in grossly obese patients.

\section{Paradoxical air embolism}

It has long been recognised that both left and right atrial pressures decrease upon assuming the erect position. ${ }^{36}$ Because the pulmonary vascular tesistance is known to increase it can be hypothesised that the left atrial pressure might decrease more than the right. In 50 per cent of patients anaesthetised in the sitting position for neurosurgery, the left atrial pressure does decrease to less than the right atrial pressure. ${ }^{36}$ This can take up to half an hour to develop fully. This change in relative pressure can have major implications for air embolus in those 30 per cent of patients who have a probe-patent 
foramen ovale, as even minute amounts of air can pass to the systemic circulation and preferentially enter the cerebral circulation. The clinical incidence of such paradoxical embolus seems low but there are at least three reports of its occurrence in association with air embolus in the sitting position. ${ }^{36,37}$ PEEP, IPPV and air embolism itself will increase the probability of an increase in right ventricular and right atrial pressures. ${ }^{37}$ In addition, moving from the supine to the erect position, causes the right atrium to move from a position above to a position below the left atrium. The pressure differential produced by this shift in position is low ( $2 \mathrm{mmHg}$ ) but is certainly in the correct direction to contribute to this potential problem in individuals at risk.

\section{Head-down positions}

The head-down position (Trendelenburg and "variations") is more complex than is apparent at first. It might be expected that the intrathoracic and intracardiac blood volume would increase and lead to an increased cardiac output. Tilts of up to $35 \mathrm{deg}$. head-down may lead to a slight increase in the right atrial filling pressure and cardiac output in the normal individual. With greater degrees of tilt, and certainly at $75 \mathrm{deg}$. head-down tilt, there is a significant decrease in right atrial filling pressure due to a drainage of blood from the heart in a cephalad direction. This is due to shift of the HIP with tilt. This shift is magnified by the use of venous occlusion cuffs around the thighs. Sequestration of blood in the veins distal to the venous occlusion cuffs leads to a decrease in blood volume in the central venous compartment and, as a result, a shift of the HIP cephalad. Similarly, the head-down position has led to a reduction of right atrial filling pressure in man in hypotensive shock. ${ }^{38}$ In animals (rats and dogs), all forms of shock, including haemorrhagic shock, are made worse by the adoption of the Trendelenburg position. ${ }^{39,40}$ In man in normovolaemic shock, the Trendelenburg position leads to a worsening of both hypotension and cardiac output. ${ }^{41}$ Where there is a decreased blood volume, the Trendelenburg position does not improve blood pressure, although there may be a slight increase in cardiac output. Haemorrhagic shock has not been studied in man but it is possible that it may correspond to the low blood volume model of Taylor and Weil. ${ }^{41}$
At present there appears to be no place for the Trendelenburg position in the management of shock in man. There is considerable evidence to suggest that maintenance of the HIP at or close to the right atrium will optimise the cardiac filling pressures and thus cardiac output. It is sufficient to elevate the legs in recumbent man to increase the venous return to the heart and increase the cardiac output. The length of the venous bed is thus effectively shortened, the bulk of the blood volume in the central compartment is maintained and the shift of the HIP away from the right atrial region is minimised.

Cerebral blood flow has been shown to decrease by 14 per cent in the head-down position. ${ }^{22}$ This implies a more significant increase in venous pressure than in carotid artery pressure. In patients with increased intracranial pressure the head down position has not led to a decrease in cerebral blood flow. However, the period of observation was short and the response to the head-down position might not have evolved fully. ${ }^{22}$ We have not discovered any report of a beneficial effect of the head-down position on cerebral blood flow.

\section{The lateral and prone positions}

It is obvious that circulatory changes due to gravitational effects on hydrostatic pressure are maximal along the long axis of the body. These gravitational effects are of lesser importance (except where intra-pulmonary gas exchange is considered) in the lateral and prone positions. In these positions, however, venous obstruction can be a major factor and may have a considerable consequence. In addition, acute flexion and/or rotation of arterial and venous channels can disturb blood flow. Specific examples include the lateral positions with the use of "kidney-rests," extremes of neck flexion, extension and rotation which impece jugular venous drainage and vertebral arterial supply, and acute truncal flexion in infants, ${ }^{42}$ obese adults and females in advanced pregnancy. In this latter category, extreme hypoxia is not uncommon and, in fact, cardiac arrest due to a presumed combination of hypoxia, vena caval obstruction and reduced cardiac output has been reported.

Increased abdominal pressure leading to inferior caval obstruction has been associated with the prone position. Abdominal compression may be caused by either an exaggerated knee-chest position or inadequate or malplaced abdominal support. 
TABLE III Respiratory system. Effect of change in body position of conscious and anaesthetised man, related to the erect-conscious position

\begin{tabular}{|c|c|c|c|c|c|c|}
\hline & $\begin{array}{l}\text { Erect } \\
\text { consclous }\end{array}$ & $\begin{array}{l}\text { Erect } \\
\text { anaesthetised } \\
\text { \& paralysed }\end{array}$ & $\begin{array}{l}\text { Supine } \\
\text { consctous }\end{array}$ & $\begin{array}{l}\text { Lateral } \\
\text { conscious }\end{array}$ & $\begin{array}{l}\text { Supine } \\
\text { anaesthetised } \\
\text { \& paralysed }\end{array}$ & Prone \\
\hline FRC & Control & $\downarrow 3 \%$ & $\downarrow 24 \%$ & $\begin{array}{l}\downarrow \text { Dependent } \\
\text { lung } \\
\uparrow \text { Non-deperdent } \\
\text { lung }\end{array}$ & $\downarrow 44 \%$ & $\downarrow 12 \%$ \\
\hline IC & & N/A & $\uparrow$ & & $\mathrm{N} / \mathrm{A}$ & \\
\hline ERV & & $\mathrm{N} / \mathrm{A}$ & $\downarrow$ & & N/A & \\
\hline VC & & $N / A$ & $\leftrightarrow, \uparrow, \downarrow$ & & $\mathrm{N} / \mathrm{A}$ & \\
\hline $\mathrm{CC}$ & & $N / A$ & $\leftrightarrow, \uparrow$ (slight) & & $\leftrightarrow, \uparrow$ (slight) & \\
\hline
\end{tabular}

Changes indicated as: $\uparrow$ increase, $\downarrow$ decrease, $\leftrightarrow$ unchanged. N/A - not applicable.

Finally, the supine position in the pregnant patient has been shown to produce inferior vena cava obstruction. The pregnant patient should be kept in the left lateral position if at all possible, and if she must be in the supine position, a left lateral tilt of $15 \mathrm{deg}$. must be utilised.

\section{The respiratory system}

Because of its effects on lung volume, distribution of inspired gases, pulmonary blood flow and cardiac output, body position has major implications in respiratory physiology. Positional changes in respiratory function are summarized in Table III.

\section{The Lung Volumes}

\section{Functional Residual Capacity (FRC)}

When man remains at rest in the erect position, his lungs are subjected to minimal pressures. The thoracic cage and the diaphragm (subjected to the gravitational pull of the weight of the abdominal contents) create a negative intrapleural pressure environment which is not uniform but more negative at the apex than at the base. Because of this gradient, and because of the greater expansive elastic forces at the apex, the alveoli at the apex are kept at a greater volume than those at the base of the lung.

When man lies down, the external forces acting on the lung change. In the supine position, the weight of the abdominal contents is transmitted through the diaphragm to the lung; in the lateral position, the more dependent lung is subjected not only to a greater intra-abdominal transmitted pressure but also to the weight of the mediastinum and its enclosed structures. This leads to a loss of lung volume particularly where these compressive forces are greatest. Pulmonary blood flow is also greatest in these same areas. Clearly, gravity is important in directing these compressive forces.

FRC decreases progressively from the erect, to the supine, to the lithotomy, to the head down and finally to the lithotomy position head down. ${ }^{43}$ The decrease in the FRC on passing from the erect to the supine position averages $800 \mathrm{ml}$. In the lateral position there is a smaller total loss of FRC, but this loss is not evenly distributed. FRC in the nondependent lung increases; FRC in the dependent lung decreases considerably. In the prone human resting on his arms and legs, loss of FRC is minimal. ${ }^{44}$ In the prone human well supported by mechanical devices, the decrease in FRC is less than that in the supine or lateral positions. ${ }^{45}$ Again, gravitational forces play an important role.

Diaphragmatic tone is important in minimising the effect of the intra-abdominal pressure on the intrathoracic contents. Diaphragmatic paralysis leads to a further decrease in FRC ( -15 per cent) in patients in the supine position. ${ }^{43}$ Interestingly, Rehder $e t$ al. found a slight decrease in FRC in anaesthetised and paralysed patients, even in the sitting position. ${ }^{46}$ This is not explicable by transdiaphragmatic pressure alone but may be due to a slightly contracted resting position of the thoracic cavity brought about by paralysis of the intercostal muscles and those muscles suspending the thorax from the cervical and dorsal spine.

There is a 20 per cent loss of FRC after induction of anaesthesia in the supine position. There is no fully accepted explanation for this; hypotheses have 
included alterations in the tone of the diaphragm, the tone of the thoracic cage and the abdominal musculature. ${ }^{43}$ FRC decreases most in the first few minutes of anaesthesia. The effect of anaesthesia and paralysis upon loss of lung volume is approxjmately the same and is not additive. Accordingly, the anaesthetised patient in the supine position does not have a further decrease of FRC with muscle paralysis. Other factors which modify the loss of FRC on induction of anaesthesia include increasing age, body build and presence of a tracheal tube. ${ }^{47}$

Sinall airways $(<1 \mathrm{~mm})$ close at low lung volumes as a result of the physical forces which induce closure in all spherical configurations. ${ }^{48}$ The tendency to closure is opposed largely by the inherent elasticity of pulmonary tissue. A measurable volume, the closing capacity, exists below which airway closure commences in the dependent areas of the lung. This volume increases with age and with many forms of pulmonary pathology. Closing capacity has been reported as being both affected ${ }^{49}$ and unaffected by postural change. ${ }^{44,50}$ The closing capacity is generally thought not to be affected by anaesthesia ${ }^{51}$ although some disagreement can be found in the literature. ${ }^{50}$ In any case, the effect of posture and anaesthesia on closing capacity is very much less than the effect on FRC.

FRC, in effect the resting lung volume, is important in relation to the closing capacity. Airway closure has been shown to occur during tidal breathing in normal subjects at about age 65 in the erect position, and at age 45 in the supine position. ${ }^{52}$ A further reduction in FRC occurs in the head down and lithotomy positions, causing airway closure to occur during tidal breathing at an even younger age. ${ }^{53}$ The further decrease in FRC following induction of anaesthesia will compound this tendency to closure, and airway closure and gas trapping have been documented in anaesthetised patients in the supine position. ${ }^{54}$ It has been shown that the intrapulmonary shunt varies with both position and age. At age 50, the shunt in the supine position is ten per cent and in the erect position four per cent. At age 70 , these values increase to 15 and five per cent respectively, ${ }^{49}$

\section{Vitol capacity}

There are conflicting reports on the effect of change of posture on the vital capacity. Vital capacity has been found to change significantly with postural change and in the same direction as the change in FRC, ${ }^{55}$ not to change significantly with posture, ${ }^{53}$ or even to increase on passing from the erect to the supine position. ${ }^{56}$ These conflicting reports can probably be reconciled. Vital capacity is comprised of the tidal volume, the expiratory reserve volume (ERV) and the inspiratory capacity. As FRC decreases with postural change in the subject with normal lungs, the ERV decreases significantly. This does not occur, however, in subjects with little ERV even in the erect position. These would include quadraplegic patients, obese patients, patients under high spinal or epidural analgesia, and patients with severe chronic obstructive lung disease who are unable to perform a forced airway manoeuvre without gas trapping.

Inspiratory capacity, on the other hand, increases as the resting position of the diaphragm is elevated on passing from the erect to the supine position, or from the erect to the erect-forward position. This may be due to an increase in resting muscle tension or to alterations in the geometric configuration of the diaphragm. In patients with increased pulmonary respiratory resistance and hyperinflation, the mechanical advantage of the diaphragm is worse in the erect position and much improved in the supine or forward-bending position. ${ }^{57}$ Whether vital capacity increases, decreases or stays the same with posture depends on which alters the most, the expiratory reserve volume or the inspiratory capacity.

\section{The distribution of inspired gases}

The regional distribution of the inspired gas is determined by the regional lung compliance, chest wall and diaphragmatic compliance, diaphragmatic mechanics and the flow rate of the inspired gas. Change in posture affects most of these determinants. ${ }^{58,59}$

Because of the gradient of pleural pressure, alveoli in the dependent regions of the lung are, at FRC, at a lower volume than those in the apex. A lower resting volume places dependent alveoli on a more compliant position of the alveolar pressure. volume curve and inspired gas is then preferentially distributed to the lower lung regions. This occurs in healthy lungs in young subjects in all body positions. ${ }^{60}$ If, on the other hand, dependent airways are closed at the onset of inspiration, gas is redistributed to non-dependent regions. 
The FRC-closing capacity relationship becomes critical in this regard, particularly for the lateral position with the greatly decreased FRC in the dependent lung. In the lateral position, redistribution of inspired gas towards the non-dependent regions of the lung occurs in some patients in the lateral position on induction of anaesthesia with spontaneous respiration ${ }^{61}$ and in almost all patients with the induction of anaesthesia and paralysis. The supine position, with its lesser inherent FRC reduction in the more dependent regions is less susceptible to this phenomenon (at least in healthy subjects). ${ }^{46}$ In the lateral position the distribution gradient of inspired gas can be restored with either large breaths or PEEP which suggests that airway closure is responsible for inspiratory gas redistribution in both the anaesthetised and anaesthetised. paralysed states. ${ }^{62}$ This issue has not been resolved. Froese and Bryan, ${ }^{63}$ and Roussos ${ }^{64}$ have produced evidence which emphasises the role of thoracic and diaphragmatic compliance in the distribution of inspired gases with positive pressure ventilation, and of the role of diaphragmatic mechanics in distributing inspired gas to dependent lung regions with spontaneous ventilation. Unfortunately some of the conclusions of Froese and Bryan are difficult to reconcile with those of Rehder who emphasises airway closure. Specifically, Bryan and Froese were unable to produce a restoration of preferential gas distribution to dependent lung with positive pressure ventilation and large breaths. This issue is important as there are implications for therapeutic manoeuvres such as PEEP and IPPV.

\section{Pulmonary blood flow}

West $e t a l .^{59}$ have defined the effect of changes in pulmonary arterial pressure (Pa), pulmonary venous pressure ( $\mathrm{PV}$ ) and alveolar pressure $(\mathrm{PA})$ on the distribution of blood flow in excised dog lungs. In a lung $30 \mathrm{~cm}$ long, the hydrostatic pressure difference of the blood is $23 \mathrm{mmHg}$ from the apical to the basal areas. Pulmonary arterial and venous blood is redistributed from non-dependent to dependent lung areas. Alveolar pressure, in effect environmental pressure, remains constant.

Three possible "zones" can be postulated relating these variables (Fig. 1).

In Zone 1, alveolar pressure is greater than either pulmonary arterial or pulmonary venous pressure and no pulmonary circulation will occur. This does

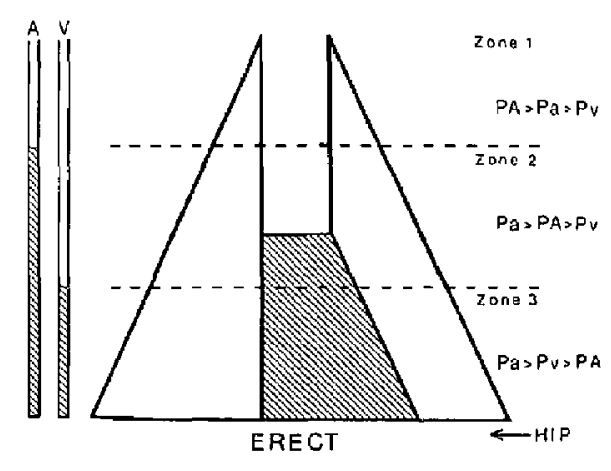

FIGURE 1 Schernatic diagram of the heart and lungs in man in the erect pasition, showing the three zones postulated by

West. ${ }^{39}$ The Hydrostatic Indifferent Point (HIP) is identified.

not arise in humans under normal circumstances. However, it could arise if the airway pressure was increased (large tidal volumes, PEEP) or if the pulmonary arterial pressure was decreased (shock).

Zone 2 conditions occur in non-dependent lung regions in both the erect and the lateral positions. In Zone 2, pulmonary artery pressure is greater than alveolar pressure which in tum exceeds pulmonary venous pressure. Pulmonary flow is determined by the difference between pulmonary artery pressure and airway pressure and will increase in the more dependent lung regions.

Under Zone 2 conditions, flow will be affected greatly by factors which alter either airway or pulmonary artery pressures.

In Zone 3, pulmonary venous pressure exceeds alveolar pressure and flow will be determined by the difference between the pulmonary artery and the pulmonary venous pressure. Because pulmonary arterial and pulmonary venous pressures should be affected in a similar fashion by gravity, flow should be less gravity dependent and more homogeneous throughout Zone 3 than Zone 2. This has been confirmed by Kaneko et al. ${ }^{60}$ who have shown that the entire pulmonary circulation is in Zone 3 in the supine and prone positions (Fig. 2). This is probably related to the relatively high position of the right atrium. In humans in the lateral position, the transition from Zone 2 to Zone 3 occurs $18 \mathrm{~cm}$. from the most dependent lung regions (Fig. 3).

The perfusion per unit lung volume should 


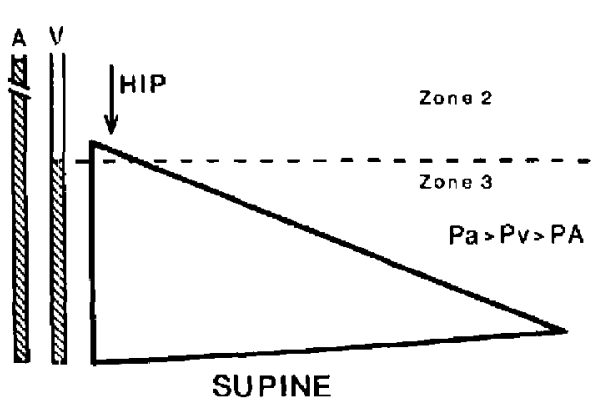

FIGURE 2 Schematic diagram of the lusgs in mant in the supine position, showing the preponderance of Zone 3 effect as defined by Kaneko et al. ${ }^{60}$ The Hydrostatic Indifferent Point (HIP) is identified.

therefore be more uniform in the supine and prone position than in the erect position.

The pulmonary interstitial pressure can impede pulmonary circulation. This will become important during major loss of lung volume and has been shown to be a factor in the most dependent regions of normal lung.

Several studies have shown a redistribution of pulmonary blood flow to the most dependent lung regions under conditions of artificial ventilation with or without anaesthesia and may be related to the magnitude of the applied airway pressure. ${ }^{65,66}$ This is important as this redistribution will generally be unmatched by ventilation. ${ }^{65,67}$

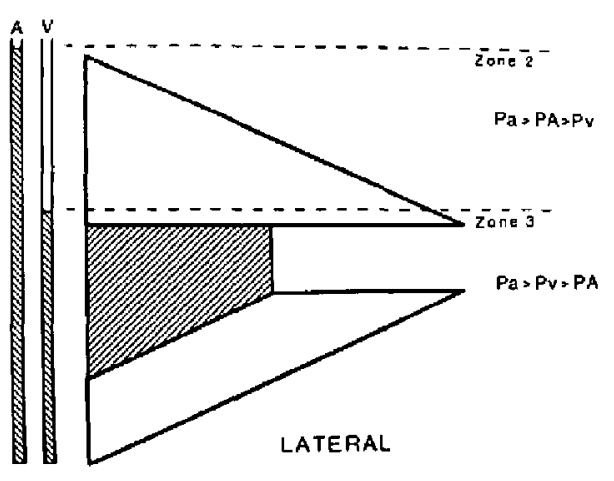

FIGURE 3 Schematic diagram of the lungs in man in the lateral position, showing the preponderance of Zone 3 effect as defined by Kaneko et al. ${ }^{59}$

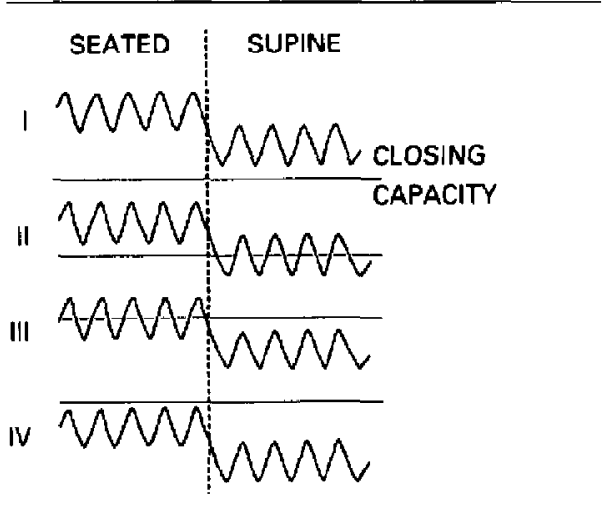

FIGURE 4 Schematic illustration of tidal ventilation and the relationship of closing capacity to functional residual capacity in the seated and supine positions. In group I, FRC exceeds closing capacity in both supine and erect positions. In group II closing capacity cxceeds functional residual capacity only in the supine position. In group III, closing capacity occurs within the range of tidal ventilation in both the sealed and supine positions. In group IV, closing capacity occurs throughout tidal ventilation, even in the erect position. See text

(Modified from Craig es $a l{ }_{1}^{68}$ with permission)

The upright posture best maintains lung volume and opposes a tendency to small airway closure, which is the main consideration for the majority of patients presenting for anaesthesia and surgery. The supine position increases diaphragmatic efficiency, cardiac output and the homogeneity of distribution of pulmonary blood volume. For any given patient, the optimal position will exist between these extremes and will be determined only by measurement.

The implications of posture in patients presenting for anaesthesia can be considered in four categories (Fig. 4) ${ }^{68}$ In the first category, there is no airway closure during tidal breathing either in the erect or supine position. With movement from the erect to the supine position, the cardiac output increases, the pulmonary blood volume becomes evenly distributed (the entire lung is Zone 3 ) and the match of ventilation and perfusion is improved. If this is a measure of optimal status, the supine position is "best" for this group.

Patients in the second category have airway closure in the dependent regions during part of their tidal ventilation in the supine but not in the erect position. These patients will have ventilation- 
perfusion mismatch in the supine position and may be better off erect. This tendency to closure is accentuated in patients in the third category who have airway closure in part of their tidal ventilation in the erect position. When they move to a supine position, airway closure will increase. Atelectasis may result if soluble gases such as nitrous oxide and oxygen are used.

Patients in the fourth and final category will have airway closure throughout their entire tidal ventilation even in the erect position. These patients are severely compromised and may be better when placed supine where the increased tendency to closure is balanced by increased cardiac output, a more evenly distributed pulmonary blood flow and more efficient diaphragmatic function. ${ }^{69}$

Posture must be chosen according to the particular needs of specific patients. The prone position may be of advantage in severely compromised patients as FRC is better maintained in this position. Furthermore, during controlled ventilation, inspired gas may be delivered specifically to the dorsal lung fields. ${ }^{45}$ In subjects with severe unilateral lung disease the lateral position with the good lung down will optimise ventilation perfusion matching. ${ }^{70}$ Finally, the supine or the erect-forward position will optimise diaphragmatic function in the asthmatic. ${ }^{57}$

The therapeutic use of any respiratory manoeuvre can only be considered after full consideration of all of the variables. For example, the effect of PEEP on cardiac output and the distribution of pulmonary blood flow may over-ride any gain derived from the recruitment of lung volume. Likewise, it has been shown that placing patients upright in the recovery room may lead to a deterioration in arterial blood oxygenation, ${ }^{71}$ perhaps due to a decrease in cardiac output.

\section{Conclusion}

The erect "active" position is man's normal or "physiological" state. Gravitational stresses, acting directly on the arteria! and venous circulations, and indirectly through diaphragmatic mechanics and intra-abdominal transmitted pressures on the lung, are important in determining the net cardiorespiratory response to change in body position.

In nomal active man, homeostatic compensatory responses maintain physiological normal ranges. In disease states, after immobility or prolonged bed rest, and in the presence of pharmacological agents, these compensatory responses may be attenuated. Under anaesthesia, the degree of compromise which will occur will be determined in part by the baseline against which the anaesthesia is induced. Consideration of all of these factors is thus important in anticipating or predicting the effects of changes in body position during anaesthesia

\section{References}

1 Gauer OH, Thron HL. Postural changes in the circulation. Ch. 67, 2409-2439. In: Handbook of Physiology. Sect. 2, Vol. 3, Eds. Hamilton WF, Dow P. American Physiological Society, Washington DC, 1965.

2 Cannon WA. The Wisdom of the Body, W.W. Norton \& Co. Inc., 1939.

3 Burch $G E$. Digital Plethysmography. New York; Grune \& Stratton. 1954.

4 Burch GE. Method for recording simultaneously the time course of digital rate and of digital volume of inflow, outflow and the difference between inflow and outflow during a single pulsc cycle in man. J Appl Physiol 1954; 7: 99.

5 Hope CE. Personal observations.

6 Wagner $E$. Fortgesetzte Untersuchungen uber den Einfluss der Schwere auf den Kreislauf. Arch Ges Physiol 1886; 39: 371.

7 Sonkodi S, Agabiti-Rosei E, Fraser R et al. Response of the renin-angiotensin-aldosterone system to upright tilting and to intravenous frusemide: effect of prior metoprolol and propranolol. $\mathrm{Br} \mathrm{J}$ Clin Pharmac 1982; 13: 341-50.

8 Williams GH, Cain JP, Dluby RG et al. Studies on the control of plasma aldosterone concentration in normal man. 1. Response to posture, acute and chronic volume depletion and sodium loading. J Clin Invest 1972; 51: 1731 .

9 Ward RJ, Danziger F, Bonica JJ et al. Cardiovascular effects of change of posture. Aerospace Med 1966; 37: 257.

10 Fournier P, Mensch-Dechene J, Ranson-Bitker $B$, Valladares $W$, Lockhart $A$. Effect of sitting up on pulmonary blood pressure, flow, and volume in man. J Appl Physiol 1979; 46: 36-40.

II Bevegard S, Holmgren A, Jonsson B. The effect of body position on the circulation at rest and during exercise, with special reference to the influence on the stroke volume. Acta Physiol Scand 1960; 49: 279-98. 
12 Rhades $J M$, Graham-Brown RAC, Sarkany I Reversible renal failure in an obese patient: hazard of sitting with feet continuously elevated. Lancet 1979; 2: 96.

13 Martin JT. The head-elevated positions. In: Positioning in anesthesia and surgery. Ed. Martin JT 1st Ed., Boston, WB Saunders Company, 1978.

14 Gaver $O H$. Die hydrostatische wirkung von bedem auf den kreislauf. Deut Med J 1955; 6: 462.

15 Dalrymple $D G$. Cardiorespiratory effects of the sitting position in neurosurgery. Вr J Anaesth 1979; 51: $1079-82$.

16 Albin MS, Janetta PJ, Maroon JC, Tung A, Millen $J E$. Anaesthesia in the sitting position. In:

Recent progress in anesthesiology and resuscitation. Amsterdam. Excerpta Medica International Congress Series No. 347, 1974.

17 Albin MS, Babinski $M$, Wolf S. Cardiovascular response to the sitting position (Letter). Br J Anaesth $1980 ; 52: 961-2$.

18 Stoelting $R K$, Viegas $O$, Campbell RL. Sodium nitroprusside-produced hypotension during anaesthesia and operating in the head-up position. Anesth Analg 1977; 56: 391-4.

$19 \mathrm{Lam}$ AM. Proper positioning of the patient. In: Anaesthetic considerations in the surgical repair of intractanial aneurysms. Ed. Varkcy GP. Intcrnational Anesthesiology Clinics Vol. 20, No. 2. Boston: Little, Brown \& Co., 1982.

20 Tindall GT, Craddock A, Greenfield JC. Effects of the sitting position on blood flow in the internal cxurotid artery of man during general anesthesia. $J$ Neurosurg. 1967; 26: 383-9.

21 Curcic $M$. The practice at some other centres - University Hospital, Zurich, Switzerland. In: Anaesthetic considerations in the surgical repair of intra. cranial aneurysms. Ed. Varkey GP. IAC Vol. 20, No. 2. Boston: Lit:le, Brown \& Co., 1982.

22 Shenkin HA, Scheuerman EB, Spitz EB, Groff RA. Effect of change of posture upon cerebral circulation of man. J Appl Physiol 1949; 2: 317-26.

23 Rishmer RF. Cardjovascular dynamics. 4th Ed. Pliladelphia; WB Saunders Company; 1976.

24 Epstein SE. Stampfer M, Beiser GD. Role of the capacitance and resistance vessels in vasovagal syncope. Circulation 1968; 37: 524-33.

25 Convertino V, Hung $J$, Goldwater D, DeBusk RF Cardiovascular responses to exercise in middleaged men after 10 days of bed rest. Circulation 1982; 65: $134-40$.
26 Wade JG, Larson PC, Hickey $R F$, Ehrenfeld WK, Severinghaus $J W$. Effect of carotid endarterectomy on carotid chemoreceptor and baroreceptor function in man. N Engl J Med 1970; 282: 823-9.

27 Tarazi $R C$, Frohlich ED, Dustan HP. Plasma volume in men with essential hypertension. $N$ Engl J Med 1968; 278: 762-5

28 Eckberg DL, Abbaud FM, Mark AL. Modulation of carotid baroreflex responsiveness in man: effects of posture and propranolol. J Appl Physiol 1976; 41: 383-7.

29 Bristow SD, Honour AS, Pickering GW, Sleight $P$, Smith $H S$. Diminished baroreflex sensitivity in high blood pressure. Circulation 1969; 39: 48-54.

30 Tarazi RC, Melsher HJ, Dustan HP. Frohlich $E D$. Plasma volume changes with upright tilt: studles in hypertension and in syncope. $J$ Appl Physiol 1970; 28 : 121-6.

31 Ekelund L-G, Eklund B, Kaijser L. Time course for the change in haemoglobin concentration with change in posture. Acta med scand 1971; 190: 335-6.

32 Bickelmann $A G$, Lippschurz EJ, Brunjes $C F$. Haemodynanics of jdiopathic orthostatic hypotension. Amer J Med 1961; 29: 26-38.

33 Morrison SC, Kumana CR, Rudnick KV, Haynes $B$, Jones $N L$. Selective and non-selective beta adrenoreceptor blockade in hypertension. Responses to change in posture, cald and exercise. Circulation 1982; 65: 1171-7.

34 Cody RJ, Franklin $K W$, Kluger J, Laragh $J H$. Mechanisms governing the postural response and baroreceptor abnormalities in chronic congestive heart failure: effects of acute and long term converting-enzyme inhibition. Circulation 1982; 66 : 135-42.

35 Murata $K$, Yamane $O$, Suga $H$. Alterations of circulatory responses to upright tilt in cardiac patients. Jpn Heart J 198 I; 22: 551-60.

36 Perkins-Pearson NAK, Marshall WK, Bedford RF. Atrial pressures in the seated position. Anesthesiology 1982; 57: 493-7.

37 Gronert GA, Messick JM, Cucchiara RF, Michen felder $J D$. Paradoxical air embolism from a patent foramen ovale. Anesthesiology 1979; 50: 548-9.

38 Sibbald WJ, Paterson NAM, Holliday RL, Baskeville $J$. The Trendelburg position: haemodynamic effects in hypotensive and normotensive patients. Crit Care Med 1979; 7: 218-24.

39 Weil MH, Whigham $H$. Head-down (Trendelen- 
burg) position for treatment of irreversible hemorthagic shock. Ann Surg 1965; 162: 905-9.

40 Guntheroth WG, Abel FL, Mullins GL. The effect of Trendelenburg's position on blood pressure and carctid flow. Surg Gynecol Obstet 1964; 119 : $345-8$.

41 Taylor J, Weil MH. Failure of the Trendelenburg position to improve circulation during clinical shock. Surg Gynecol Obstet 1967; 124: 1005-10.

42 Spahr RC, MacDonald HM, Mueller-Heubach $E$. Knee-chest position and neonatal oxygenation and blood pressure. Amer J Dis Child 1981: 135: $79-80$.

43 Nunn JF. Applied Respiratory Physiology. 2nd Ed. London; Butterworths; 1977.

44 Agostini E, Mead J. Statics of the respiratory system. In: Handbook of Physiology, Sec 3, Respiration, Vol. 1, Eds. Fenn WO, Rahn H. American Physiological Society, Washington, DC.; 1964; 387-409.

45 Douglas WW, Rehder $K$, Beynen $F$, Sessler $A$, Marsh $M$. Impaired oxygenation in patients with acute respiratory failure: the prone position. Am Rev Respir Dis 1977; 115: 559-66.

46 Rehder $K$, Sessler $A D$, Rodarte JR. Regional intrapulmonary gas distribution in awake and anesthetised paralysed man. J Appl Physiol 1977; 42: 391-402.

47 Hickey RF, Visick W, Fairley HB, Fourcade HE. Effects of halothane anacsthesia on functional residual capacity and alveolar-arterial oxygen tension difference. Anesthesiology 1973; 38: 20-42.

48 Burger EJ, Macklem P. Airway closure: demonstration by breathing 100 s oxygen at low lung volumes and by nitrogen washout. J Appl Physiol 1968; $25: 139$.

49 Don HF, Craig DB, Wahba WM, Couture JG. The measurement of gas trapped in the lungs at functional residual capacity and the effects of posture. Anesthesiology 1971; 35: 582-90.

50 Rehder $K$. Sessler $A D$, Marsh HM. General anesthesia and the lung. Am Rev Respir Dis 1975; 112: 541-63.

51 Gilmour I, Burnham M, Craig DB. Closing capacity measurement during general anesthesia. Anesthesiology 1976; 45: 477-82.

52 LeBlanc P, Ruff F, Milic-Emili J. Effects of age and body position on "airway closure" on man. J Appl Physiol 1970; 28: 448-51.
53 Craig DB, Wahba WM, Don HF. Airway closure and lung volumes in surgical positions. Can Anaesth Soc J 1971; 18; 92-8.

54 Don $H F$, Wahba WM, Craig DB. Airway closure, gas trapping and the functional residual capacity during anaesthesia. Anesthesiology 1972; 36 : 533-9.

55 Wade OL, Gilson JC. The effect of posture on diaphragmatic movement and vital capacity in normal subjects with a note on spirometry as an aid in determining radiological chest volumes. Thorax 1951; 6: 103-26.

56 Cameron GS, Scot JW, Jousse AT, Botterell EH. Diaphragmatic respiration in the quadraplegic patient and the effect of position on his vital capacity. Ann Surg 1955; 141: 451-6.

57 Druz WS, Sharp JT. Electrical and mechanical activity of the diaphragm accompanying body position in severe chronic obstructive pulmonary disease. Am Rev Respir Dis 1982; 125: 275-80.

58 Milic-Emili J. Regional distribution of inspired gas in the lung. J Appl Physiol 1966; 21: 749.

59 West JB. Respiratory Physiology - the essentials. Baltimore; The Williams and Wilkins Company; 1974.

60 Kaneko K, Milic-Emili J, Dolovich MB, Dawsan $A, B a t e s D V$. Regional distribution of ventilation and perfusion as a function of body position. $J$ Appl Physiol 1966; 21: 767-77.

61 Rehder $K$, Sessler AD. Function of each lung in spontaneously breathing man anesthetised with thiopental-meperidine. Anesthesiology 1973; 38: $320-7$.

62 Rehder $K$, Wenthe FM, Sessler $A D$. Function of cach lung during mcchanical ventilation with ZEEP and with PEEP in man anesthetised with thiopentalmeperidine. Anesthesiology 1973; 39: 597-606.

63 Froese $A B, B$ yan $A C$. Effects of ancsthesia and paralysis on diaphragmatic mechanics in man. Anesthesiology $1974 ; 41: 242-55$.

64 Roussas CS, Fixley M, Genest J er al. Factors influencing the distribution of inspired gas. Amer Rev Respir Dis 1977; 116: 457-74.

65 Chevrolet JC, Martin JG, Flood R, Martin RR, Engel $L H$. Topographical ventilation and perfusion distribution during IPPB in the lateral posture. Am Rev Respir Dis 1978; 118: 847-54.

66 Hulands GH, Greene R, CliffLD, Nunn JF, Influence of anaesthesia on the regional distribution of 
perfusion and ventilation in the lung. Clin Sci 1970; 38: 451-60.

67 Denlinger SK, Kallos T, Marshall BE. Pulmonary blood flow distribution in man anesthetised in the lateral position. Anesth Analg 1972; $51: 260-3$

68 Craig $D B$, Wahba WM, Don $H F$. Closing volume and its relationship to gas exchange in seated and supine positions. J Appl Physiol 1971; 31: 717-21.

69 Barach AL, Beck GS. The ventilatory effects of the head-down position in pulmonary emphysema. Amer J Med 1954; 16: 55-60.

70 Ibanez J, Rourich $R$, Abizanda $R$, Claramonte $R$, Ibanez $P, B$ Bergada $J$. The effect of lateral positions on gas exchange in patients with unilateral lung disease during mechanical ventilation. Intensive Care Med 1981; 7: 231-4.

71 Russel $W J$. Position of patient and respiratory function in the immediate postoperative period. $\mathrm{Br}$ Med J 1981; 283: 1079-80. 